\title{
PERANCANGAN INFOGRAFIS PASAR MUAMALAH SEBAGAI AWAL KEMBALINYA DINAR DIRHAM
}

\author{
Bintang Islam ${ }^{1)}$, Muhamad Fajar ${ }^{2)}$ \\ Program Studi Desain Komunikasi Visual \\ Fakultas Bahasa dan Seni Universitas Indraprasta PGRI \\ Jl. Nangka 58C Tanjung Barat, Jakarta Selatan, 12530, Indonesia \\ islam.bintang@gmail.com
}

\begin{abstract}
Abstrak
Dilatarbelakangi praktik pasar saat ini dengan prinsip kapitalisme, banyak terjadi penipuan jual beli dan ketidakjelasan akad. Sulit menghindari praktik riba dan sistem keuangan yang menggunakan uang kertas yang dikembangkan oleh negara-negara barat dalam kurun waktu yang berbeda menyebabkan nilai tukar yang menyusut. Pasar Muamalah menjadi pasar yang menerapkan nilai nilai syariah di dalamnya. Dengan menggunakan mata uang dinar dirham dalam setiap transaksinya, menegaskan adanya akad jual beli, menghindarkan jual beli dari praktik riba karena nilai dinar dirham relatif stabil sepanjang zaman sehingga tidak terjadi penyusutan nilai tukar. Kegiatan Muamalah dalam bidang perdagangan merupakan suatu potensi yang memberikan peluang yang besar terhadap kemajuan dan perkembangan umat Islam. Oleh karena itu dibutuhkan media informasi yang berisi keunggulan pasar Muamalah yang menggunakan dinar dirham dengan pasar biasa yang menggunakan uang kertas dan koin. Perancangan media informasi ini akan dilakukan dengan metode penelitian kualitatif.
\end{abstract}

Kata Kunci: Pasar Muamalah, Dinar Dirham, Infografis

\begin{abstract}
Against the background of current market practices with the principle of capitalism, there are many buying and selling scams and unclear contracts, it is difficult to avoid usury practices and the financial system that uses paper money developed by western countries in different periods of time causing the exchange rate to shrink. Muamalah Market is a market that applies sharia values in it, using the dirham currency in every transaction, making the sale and purchase agreement clear and avoiding usury practices, because the value of the dirham dinar is relatively stable throughout the ages so that there is no depreciation in the exchange rate. Muamalah activity in the field of trade is a potential that provides great opportunities for the progress and development of Muslims. Therefore, we need information media that contains Muamalah market advantages that use the dinar dirham with ordinary markets that use paper money and coins.
\end{abstract}

Keywords: Muamalah Market, Dinar Dirham, Infographic

Correspondence author: Bintang Islam, islam.bintang@gmail.com, Jakarta, and Indonesia

This work is licensed under a $C C-B Y-N C$ 


\section{PENDAHULUAN}

Pasar Muamalah menjadi pasar yang menerapkan nilai nilai syariah di dalamnya. Pasar tersebut sangat berdampak baik untuk diterapkan dalam daerah yang memiliki penduduk muslim, karena menguntungkan bagi penjual juga pembeli. Pasar ini tidak mengambil biaya sewa dan pajak. Selain itu, praktik riba sangat dilarang dalam setiap transaksi jual beli kebutuhan, setiap transaksi menggunakan uang dinar emas dan dirham perak tidak menggunakan uang rupiah baik kertas maupun koin, karena sistem keuangan yang dikembangkan oleh Negara-negara barat adalah dengan menggunakan uang kertas. Efek samping akibat penggunaan uang kertas dalam kegiatan ekonomi yang menjadikan uang sebagai alat transaksi adalah nilainya akan berubah dalam setiap kurun waktu yang berbeda karena nilainya akan mengalami perubahan tergantung dari kondisi suatu negara itu sendiri. Sedangkan nilai tukar dinar dan dirham relatif stabil sejak zaman dahulu, karena mata uang ini memiliki nilai intrinsik sendiri.

Dilatarbelakangi praktik pasar saat ini yang menggunakan prinsip kapitalisme, sering terjadi penipuan dalam proses jual beli dan ketidakjelasan akad, sulit menghindari praktik riba dan sulit menerapkan sunnah ber-Muamalah (yaitu pembayaran dengan dinar dan dirham). Sebagaimana pendapat Qardhawi (1997) bahwa Islam adalah agama yang mengatur tatanan hidup dengan sempurna, kehidupan individu dan masyarakat, baik aspek rasio, materi, maupun spritual, yang didampingi oleh ekonomi, sosial, dan politik. Kegiatan Muamalah dalam bidang perdagangan merupakan suatu potensi yang memberikan peluang yang besar terhadap kemajuan dan perkembangan umat Islam. Dalam hal jual beli akan terjadi perputaran sistem perekonomian yang melibatkan banyak pihak, seperti pemerintah, perusahaan, pengusaha, maupun masyarakat umum. Sehingga, kegiatan jual beli memberikan potensi yang amat besar dalam mendapatkan rezeki yang lebih besar. Adanya Pasar Muamalah diharapkan mampu mengatasi itu semua dan memfasilitasi pihak tertentu yang ingin melakukan praktik jual beli sesuai dengan peraturan pasar yang didasarkan pada Syariah. Namun, keberadaan model pasar seperti ini belum banyak disoroti oleh orang-orang sehingga sulit untuk berkembang lebih besar. Meskipun begitu, berjalannya pasar ini layak diamati sebagai norma baru yang lahir dari praktik pasar seperti ini. Hal ini tentu menjadi perhatian terhadap keberadaan Pasar Muamalah, untuk itu perlu adanya ide kreasi dan penciptaan sebuah media representasi visual dalam memberikan pemahaman serta informasi untuk lebih memudahkan khalayak memahami keberadaan serta praktik dalam Pasar Muamalah Tersebut.

Seiring dengan perkembangan zaman, kegiatan menyampaikan pesan semakin mudah. Untuk menarik perhatian generasi sekarang ini agar mau mempelajari ajaran agama dan melanjutkan sunnah yang ada harus menggunakan pendekatan visual yang lebih menarik, dalam hal ini infografis bisa menjadi salah satu alternatif. Infografis merupakan representasi visual dari informasi, data atau pengetahuan. Infografis menggabungkan informasi dengan grafis menjadi satu sehingga memungkinkan untuk lebih memahami maksud yang terkandung dalam informasi dengan lebih baik dan lebih mudah. Proses komunikasi ini dapat menyajikan informasi yang kompleks dengan cara yang lebih cepat dan lebih mudah dipahami dibandingkan dengan informasi hanya dalam bentuk teks.

\section{METODE PENELITIAN}

Metode yang digunakan oleh peneliti adalah Metode Kualitatif, suatu penelitian yang baik senantiasa memperhatikan keselarasan antara teknik yang digunakan dan alur pemkiran umum beserta gagasan teoritis. Tujuan penggunaan metode kualitatif adalah mencari pengertian yang mendalam terhadap suatu masalah, sehingga bisa mendapatkan solusi dari penjabaran masalah yang telah dilakukan (Raco, 2010).

Untuk memperoleh data, peneliti menggunakan metode riset dari berbagai studi pustaka yang menggunakan referensi jurnal yang berkaitan dengan materi yang sesuai dengan penelitian ini. 


\section{HASIL DAN PEMBAHASAN}

Pasar adalah tempat berkumpulnya pedagang dan pembeli yang melakukan transaksi barang atau jasa. Pasar merupakan sebuah mekanisme pertukaran barang dan jasa yang alamiah dan telah berlangsung sejak awal peradaban manusia. Dalam Islam pasar sangatla penting dalam kegiatan perekonomian. Pasar sudah ada pada masa Rasulullah SAW dan Khulafaur Rasyidin dan menjadi Sunatullah yang telah di jalani selama berabad-abad (P3EI, 2011). Pasar yang selama ini berjalan khususnya di Indonesia hanya bertujuan agar upaya pemaksimalan untuk mencari untung yang sebesar-besarnya dan cenderung fokus pada kepentingan sendiri. Sistem tersebut nampaknya kurang baik untuk diterapkan dengan sistem ekonomi syariah yang menekankan konsep manfaat yang lebih besar pada kegiatan ekonomi termasuk didalamnya sistem pasar dan pada kegiatan ekonomi itu mengacu kepada konsep maslahat dan menjunjung tinggi asas-asas keadilan. Selain itu pula, menekankan bahwa pelakunya selalu menjunjung tinggi etika dan norma hukum dalam kegiatan ekonomi. Realisasi dari konsep syariah itu memiliki tiga ciri yaitu adanya keadilan, menghindari yang dilarang dan memperhatikan aspek kemanfaatan. Ketiga prinsip tersebut berorientasi pada terciptanya sistem ekonomi yang seimbang yaitu keseimbangan antara memaksimalkan keuntungan dan pemenuhan prinsip syariah yang menjadi hal mendasar dalam kegiatan pasar (Ali, 2008).

\section{Definisi Muamalah}

Muamalah berarti transaksi bilateral di semua bidang kehidupan, baik itu sosial, ekonomi, politik atau spiritual. Penerapan hukum, yaitu Fiqih, berkaitan dengan Muamalah bertujuan untuk mengatur perilaku manusia di antara mereka sendiri. Meskipun tulisan-tulisan Imam Malik, Imam Syafi'I dan At-Tabari merujuk ke Muamalah sebagai penentuan transaksi perdagangan dan operasi kredit, perlu diingat bahwa pernikahan, perceraian, warisan dan sebagainya juga merupakan Muamalah. Menjadi sunnatullah bahwa manusia harus berinteraksi dengan masyarakat dalam rangka saling tolong menolong (ta'awun) dan saling membantu antara satu dengan yang lainya. Sebagai makhluk sosial, manusia menerima dan memberi kepada orang lain. Ber-muamalah bertujuan untuk memenuhi kebutuhan hidup dan kehidupan dalam rangka mempertahankan untuk mencapai kemajuan dalam hidupnya.

Praktik muamalah yang selalu dilakukan oleh manusia adalah praktik transaksi jual beli barang, yakni saling tukar menukar antara barang dengan barang lainnya yang dilakukan oleh dua orang atau lebih dari satu pihak. Memahami praktik jual beli dalam pasar merupakan hal yang penting, karena setiap manusia pasti akan melakukannya. Jika umat muslim harus terikat kepada hukum syara' dalam setiap hal yang diperbuatnya, maka praktik transaksi jual beli merupakan salah satu perbuatan yang selalu dilakukan dan harus dilandasi oleh hokum syara'. Di Indonesia terdapat sebuah pasar tradisional yang berbeda dengan pasar pasar lainnya. Dinamakan pasar ini sebagai "Pasar Muamalah" karena pasar ini menerapkan unsur unsur syariah didalamnya. Beberapa daerah di Indonesia telah menerapkan Pasar Muamalah dalam Pasar Tradisional, seperti di daerah Depok, Jawa Barat, lalu di daerah Ketapang, Kalimantan Barat, dan di daerah Tanjung Pinang, Pulau Bintan, Kepulauan Riau (Isfandiar, 2009; Jamaluddin, 2017; Lubis, 2018).

\section{Dinar dan Dirham}

Sesungguhnya, dalam sejarah perkembangan sistem ekonomi dunia, emas sudah dikenal sejak 40.000 tahun SM. Hal itu ditandai penemuan emas berbentuk kepingan di Spanyol, yang saat itu digunakan oleh paleiothicman. Sejarah lain menyebutkan bahwa emas ditemukan oleh Mesir kuno (circa) 3000 tahun SM. Sedangkan sebagai mata uang, emas mulai digunakan pada zaman Raja Turki yaitu Lydia sejak 700 tahun SM. Sejarah penemuan emas sebagai alat transaksi dan perhiasan tersebut kemudian dikenal sebagai barbarous relic (Keynes dalam Idris, 2006). Pada zaman Rasulullah SAW dikenal dua jenis uang yaitu uang yang berupa komoditi logam dan koin yang berasal dari kekaisaran Roma (Byzantine). Dua jenis uang logam yang digunakan adalah emas (Dinar) dan perak (Dirham). Logam tembaga juga digunakan secara terbatas dan tidak sepenuhnya dihukumi sebagai uang, disebut fulus. 
Tercatat bahwa Dirham dibuat pertama kali pada saat zaman Kekalifahan Umar bin Khattab pada sekitar abad $18 \mathrm{H}$, meskipun demikian koin logam emas dan perak dari Byzantium tetap diterima oleh kalangan umat Islam. Dinar dibuat pertama kali pada saat zaman Kekalifahan Mu'awiya bin Abu Sufyan 41-60 H. Meskipun demikian, koin emas dan perak dari Byzantine tetap digunakan sampai sekitar tahun $75 \mathrm{H}-76 \mathrm{H}$ pada zaman Kekhalifahan Abdul Malik bin Marwan. Kekhalifahan yang terakhir ini melakukan reformasi finansial dan mulai saat itu hanya Dinar dan Dirham yang dibuat sendiri oleh Kekhalifan Islam yang berlaku (Nur, 2010:33). Dinar emas adalah koin emas 22 karat, seberat 4,25 gram, dengan diameter $23 \mathrm{~mm}$. Sedangkan dirham perak adalah koin perak murni, seberat 3 gram, dengan diameter $25 \mathrm{~mm}$. Sepanjang sejarah islam, dua koin inilah yang berlaku sebagai alat tukar dan alat pembayaran, atau uang (nuqud). Begitu pula, hanya dengan emas dan perak, dinar dan dirham, zakat dihitung dan dibayarkan. Bukti terakhir hal ini dapat dilihat pada ketetapan hukum di Daulah Utsmani, yang menyebutkan hanyalah emas (dinar) dan perak (dirham) berlaku sebagai uang. Uang kertas, tidak dapat diterima sebagai alat pembayaran. Ketentuan formal ini terus berlaku sampai tahun 1926, dua tahun sejak berakhirnya Kekhalifahan Utsmani pada Maret 1924. Koin dinar emas dan dirham perak kembali dicetak pada tahun 1992, oleh kaum Muslimin di Granada, Spanyol. Sampai saat ini koin dinar dan koin dirham telah dicetak di berbagai tempat, termasuk di Dubai, Malaysia, dan Indonesia. Secara khusus, Indonesia memiliki prospek yang bagus sebagai tempat terbaik bagi penerapan ekonomi berbasis dinar emas dan dirham perak atau muamalat.

Di Indonesia sendiri, sesungguhnya sejak tahun 1999 sudah mulai ada gerakan untuk menggunakan dinar dirham sebagai alat tukar dan alat transaksi. Gerakan tersebut di prakarsai oleh beberapa tokoh misalnya Zaim Saidi dan lain-lain yang kemudian meluas dan dikenal berbagai lapisan masyarakat, sehingga pada ahirnya terbentuklah PT.Islamic Mint Nusantara (IMN) yang merupakan lembaga pencetakan dinar dirham di Indonesia dengan berbagai macam produknya, misalnya Wakala atau yang disebut kios dinarfirst dan sebagainya. Sementara itu standarisasi terhadap dinar dan dirham, Nabi Muhammad SAW, menerapkan kaidah standarisasi dinar dan dirham ini sesuai dengan "(berat) 7 Dinar harus setara dengan (berat) 10 Dirham" (Muklisin, 2013; Rahmi, 2015).

\section{Konsep Dasar Perancangan Infografis Analisis khalayak}

Konsep dasar perancangan infografis pasar Muamalah sebagai awal kembalinya dinar dirham sebagai informasi yang dituju dari perancangan infografis ini. Berikut adalah penjelasan mengenai analisis khalayak yang dituju dari segi demografis, geografis, psikografis. Segmentasi Rancangan visual yang kreatif dapat menarik perhatian audiens atau masyarakat. Secara demografis masyarakat yang cocok menjadi target adalah semua jenis kelamin, terutama dewasa pada umur 20-50 tahun. Dengan status sosial berada pada tingkat ekonomi menengah hingga menengah ke atas. Target pada dewasa ini terutama para pedagang dan pengusaha serta masyarakat khususnya muslim memiliki peranan dalam menerapkan sunnah dalam Muamalah terutama praktik jual beli yang diterapkan pada pasar Muamalah.

Segmentasi berdasarkan geografis masyarakat yang menjadi target adalah daerah perkotaan dan pinggiran kota, karena di awal perkembangannya pasar Muamalah ini diadakan di setiap perkotaan hingga pinggiran kota, dengan ini memungkinkan target yang dituju akan bisa tercapai. Segmentasi secara psikografis khalayak yang dituju adalah masyarakat yang memiliki religiusitas dalam menerapkan sunnah Muamalah ini. Infografis ini bertujuan mengubah paradigma masyarakat terhadap pasar Muamalah dengan memadukan pendekatan konsep visual yang menarik dengan representasi visual dari informasi yang disampaikan. Dengan menyajikan informasi dan data mengenai norma dan praktik yang ada dalam pasar Muamalah tersebut. 


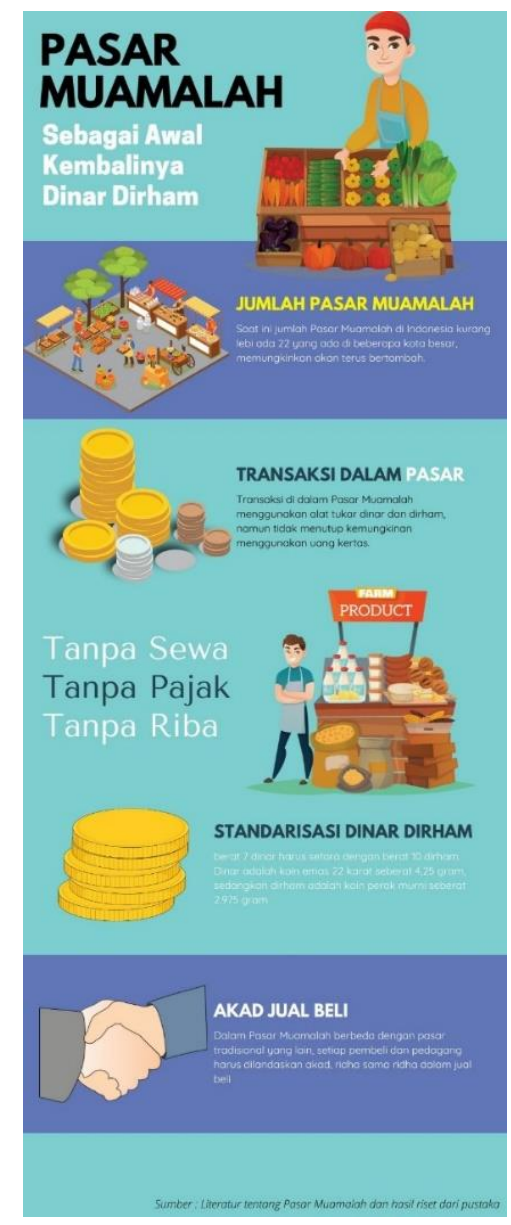

Gambar 1. Media Infografis

\section{Konsep Visual}

a. Gaya Visual

Gaya visual yang dipilih dalam infografis ini menggunakan flat design, gaya ini terkesan sederhana tetapi dapat menarik perhatian terhadap target khalayak yang dituju. Gaya visual ini juga popular dan digunakan oleh para kreator dalam membuat karya desain. Perancangan dengan konsep ini bertujuan agar pesan yang disampaikan dapat dimengerti dan dipahami oleh segmentasi yang dituju.

b. Ikon

Ikon yang digunakan adalah representasi dan penyederhanaan objek dengan menggunakan flat design dengan sederhana tanpa mengilangkan bagian yang menjadi ciri khas dan karakteristiknya.

c. Skema dan Dasar Pemilihan Warna

Warna bersangkut paut dengan persepsi dan interpretasi subyektif. Bahkan jika mereka melihat obyek yang sama, orang akan menggambarkannya dengan referensi dan pengalaman yang berbeda (Dameria). Warna merupakan komponen penting dalam penciptaan suatu karya. Warna mempresepsikan bentuk sehingga dapat dikenali dan warna merupakan salah satu elemen yang penting dalam sebuah desain (Listya, 2018). Dalam pemilihan warna, perlu diperhatikan target khalayak dan segmentasi yang dituju untuk menciptakan kesan dan suasana dalam infografis.

Tema warna yang digunakan adalah warna selaras harmonis dengan warna turunannya dan warna pendukungnya yaitu warna merah, oranye, hijau dan biru sebagai penegas dan 
penyeimbang. Kombinasi warna turunan cocok diterapkan pada media infografis dinamis. Menurut teori susunan warna (Anggraini \& Nathalia, 2014), kombinasi warna harmonis terlihat lembut karena perpaduan warna satu dengan warna lain dengan perubahan halus, tema warna turunan dapat membuat audiens tidak bosan untuk berlama-lama melihat infografis.

Warna yang digunakan dalam infografis ini di antaranya biru dan merah serta warna turunannya. Kesan warna biru memberi kesan kejelasan, ketenangan, dan keberhasilan. Warna biru memiliki efek menenangkan pikiran serta membantu memusatkan fokus khalayak dalam membaca infografis ini. Warn aini kemudian merepresentasikan pasar. Selanjutnya, warna merah dapat merepresentasikan tempat terhadap pedagang. Warna ini memiliki kesan meningkatkan perhatian terhadap khalayak.

d. Pemilihan Huruf

Anggraini dan Nathalia (2014: 58-63) menjelaskan tentang klasifikasi huruf, yaitu Serif terdiri dari Old style, Transitional, Modern dan Egyptian (Slab Serif). Slab Serif memiliki badan yang lebih tebal. Selain Serifjuga ada kategori Sans Serif yang diartikan tanpa sirip atau tanpa sirip. Jadi, huruf jenis ini tidak memiliki sirip tambahan pada ujung hurufnya dan memiliki ukuran ketebalan huruf yang sama. Sans Serif melambangkan kesederhanaan, lugas berkesan masa kini. Huruf berjenis ini sangat bagus untuk berdampingan dengan grafis yang terlihat modern. Huruf yang dipilih menggunakan jenis font Baloo Reguler, merupakan jenis huruf sans serif atau tidak berkait. Klasifikasi huruf bertujuan untuk memudahkan mengidentifikasi, memilih typeface yang akan digunakan, dan memberikan beragam makna (Raden). Dalam perancangan ini klasifikasi huruf yang digunaka adalah serif, sans serif, dan old style (Rosyidah \& Listya, 2019; Astuti \& Ula, 2020).

\section{SIMPULAN}

Masih banyaknya masyarakat yang kurang mengerti dengan konsep Pasar Muamalah menyebabkan penafsiran yang berbeda, juga kurangnya sosialisasi sehingga mendapatkan kesan yang kurang menarik pada masyarakat, maka dari itu dibutuhkan media informasi yang dapat merubah kesan masyarakat. Apalagi saat ini banyak masyarakat yang ingin terus mendalami agama melalui kajian kajian agama, juga dakwah dakwah dengan gambar atau konten yang menarik perhatian sehingga tersampaikan informasi kepada masyarakat. Dengan memberikan informasi tentang Pasar Muamalah dan penggunaan Dinar Dirham melalui media infografis, diharapakan masyarakat terutama kaum muslim bisa lebih mengerti bagaimana jalannya pasar yang didasarkan hukum Islam berdasarkan syariah sehingga tidak adanya ketidak jelasan akad jual beli, dan juga harga barang yang sesuai dengan nilai tukar, tidak seperti praktik pasar saat ini dengan prinsip untung sebesar besarnya dengan cara apapun dan penggunaan uang kertas yang semakin lama akan semakin menyusut nilainya. Sehingga menguntungkan banyak pihak, mulai dari masyarakat yang membeli karena harga kebutuhan yang tidak terlalu mahal, pedagang yang tidak membayar sewa dan pajak sehingga tidak memahalkan barang dagangan apalagi sampai riba.

\section{DAFTAR PUSTAKA}

Anggraini, S., \& Nathalia, K. (2014). Desain komunikasi visual: Dasar-dasar panduan untuk pemula. Bandung: Nuansa Cendekia.

Astuti, W., \& Ula, R. N. (2020). Infografis Statis Teknik Dasar Renang untuk Anak Sekolah Dasar. Visual Heritage: Jurnal Kreasi Seni dan Budaya, 2(2), 136-143.

Isfandiar, A. A. (2009). Akad muamalah di pasar modal syariah. Jurnal Hukum Islam (JHI), 7(1), 89-105.

Jamaluddin, J. (2017). Konsep dasar muamalah \& etika jual beli (al-Ba'i) Perspektif Islam. Jurnal Pemikiran Keislaman, 28(2), 289-316. https://doi.org/10.33367/tribakti.v28i2.485 
Listya, A. (2018). Konsep dan Pengunaan Warna dalam Infografis. Jurnal Desain, 6(01), 10. https://doi.org/10.30998/jurnaldesain.v6i01.2837

Lubis, A. A. (2018). Analisis Aspek Religiusitas Terhadap Etika Bisnis Pedagang Pasar Muslim Pusat Pasar Kota Medan. Jurnal Dusturiah, 7(1). https://jurnal.arraniry.ac.id/index.php/dustur/article/view/2339

Muklisin, M. (2013). Ikhtiar menjadikan dinar-dirham sebagai mata uang di Indonesia. Equilibrium, 1(2), 258-278.

Raco, J. R. (2010). Metode penelitian kualitatif: Jenis, karakteristik dan keunggulannya. Jakarta: Grasindo

Rahmi, A. (2015). Mekanisme Pasar dalam Islam. Jurnal Ekonomi Bisnis dan Kewirausahaan, 4(2), 177. https://doi.org/10.26418/jebik.v4i2.12481

Rosyidah, E. N., \& Listya, A. (2019). Infografis dampak fisik dan psikologis pernikahan dini bagi remaja perempuan. Visual Heritage: Jurnal Kreasi Seni dan Budaya, 1(03), 191-204. 